\title{
Plights and Solutions of Enterprise Human Resource Management Feipeng Liu
}

\author{
Department of Management, Shaanxi Vocational and Technical College, Xi'an, 710100, China
}

Keywords: enterprise; human resource management; plight; strategy

\begin{abstract}
Human resource management is a very significant content in modern enterprise management and has key strategic significance for enterprise survival and development. This paper discusses the implication of human resource management, analyzes the plights of enterprise human resource management and proposes the strategies to solve the plights.
\end{abstract}

\section{Introduction}

Under the new situation and especially under the condition of substantial reform of China's employment system, human resource management strategy as one of very important management strategies must alter subjective, single and laggard thinking mode, fully apply modern management ideas, actively innovate for enterprise personnel management system and actively carry out reform of human resource reserve, salary and target management so that enterprise human resource management can quickly adapt new situations and integrate with international situations and make enterprises adapt the demand of modern market competitions.

\section{Implication of human resource management}

Human resource management stems from traditional personnel management and is based on human capital. It is one of the most important enterprise assets. It starts from improving enterprise management level and economic benefit, including human resource planning, staff recruitment, personnel training, personnel development, performance appraisal and salary administration. Human resource management as an inter-discipline involves many fields of enterprise management in the aspect of the connotation and extension. Nowadays, human resource management has become an important content in enterprise strategic management and also becomes an important problem including improvement of competition capacity and economic benefit.

\section{Plights of enterprise human resource management}

\section{(I) lack of overall planning}

A large number of enterprises realize overall human resource planning has special functions under the situations of market competitions. However, most enterprises do not take actual actions. Specific operation has a large gap with awareness. Some enterprises fundamentally fail to cognize the outstanding functions of overall human resource planning. In the face of every-changing economic development situations, large quantities of Chinese enterprises only pay attention to short-term economic benefit and neglect long-term development strategy so that it is hard to maintain enterprise survival.

\section{(II) Imperfect human resource management system}

Human resource management is a very important constituent part of enterprise operation and management. However, quite a number of Chinese enterprises are still at the level of office management in terms of human resource management or only focus on some functions in human resource management. They fail to form comprehensive and systematical human resource management system. Thus, human resource management effects are greatly affected. For example, some enterprises which pay attention to human resource management introduce career planning technology for personnel, but fail to make necessary adjustments of personnel promotion, training and reserve mechanisms. Thus, various methods and technologies generate contradictions in the enterprise. Finally, the plan has to be terminated. 


\section{(III) Low status of human resource department}

Due to the limits of functions and power, it is difficult for human resource department of an enterprise to keep smooth communications with other business departments. The human resource department as an internal department only provides corresponding services and support or business departments, but lacks comprehensive, in-depth and meticulous understanding of overall operation thought. Thus, it lacks insight ability. Therefore, human resource management way can only adopt repair after the event. It is hard to implement real human resource planning. The specific work of human resource department is detained under the supervision layer so that various problems appear such s imperfect evaluation system and personnel training plan.

\section{(IV) Indifference for employee training}

Some enterprises cannot take out sufficient funds to carry out induction training and on-the-job training due to limited economic strength or other factors. The entrepreneur and the management layer often consider the return rate of training is too low. Besides, employees may select job-hopping after the training. Meanwhile, it will take much time to train personnel. Thus, time cost is generated. This will also influence production and management of the enterprise.

\section{(V) Lack of incentive mechanism effects}

Currently, since education level of entrepreneur teams of some enterprises is generally low, they lack enough theoretical support. This will inevitably weaken management foundation. So, they cannot formulate incentive mechanism in a meticulous and intensive way. They often adopt sweeping approach and completely ignore individual demands of employees. Meanwhile, the entrepreneur and the management layer often consider incentive too single and think incentive is equal to money award and penalty. Moreover, in some small and medium enterprises, the implementation of incentive mechanism will alter with the mood of leaders so that employees are at loose ends. In this way, it is hard to play the role of incentive mechanism.

\section{(VI) Lack of cultural construction}

Chinese enterprise often stress material level during enterprise cultural construction, and neglect the functions of enterprise core value and actual conditions of the enterprises so that enterprise cultural construction is machine-made and lacks uniqueness. Even many enterprises do not implement enterprise cultural construction.

\section{Strategies to solve plights of enterprise human resource management}

\section{(I) To lay emphasis on overall planning of human resource management}

To gain long-term development, an enterprise must establish the idea of people first, give up obsolete thought, absorb advanced management ideas of other enterprises or western developed countries and enhance personnel training awareness. To respect personnel, enterprises should pay attention to personnel incentive and cultivation, boost employees' job satisfaction to the largest extent, apply enterprise environment and enterprise culture to help employees cognize and develop themselves, make work and personnel adapt and coordinate mutually and finally realize win-win (enterprise development and personnel development). Enterprise managers must focus on the important functions of human resource management department. The human resource management department should recruit appropriate employees and especially give play to positive roles of the person in charge of human resource department. In a bid to make sure human resource planning and enterprise development strategy prepared by human resource department can keep consistent, the enterprise should own sufficient personnel reserve.

\section{(II) To perfect construction of human resource management system}

Enterprises should prepare new human resource management system with consistent long-term targets and macroscopic strategic targets. During construction of human resource management system, enterprises must overall plan various functions of human resource management and make it serve macro-management strategy. It is not easy for enterprises to design human resource management system complying with their development. This is because the personnel proficient in human resource management system are very few in some enterprises. So, enterprises need to employ the experts from management consulting companies with rich experience to help them 
prepare rational human resource management system. Only in this way, enterprises can better prepare feasible human resource management system to lay good of foundation for sustainable development.

\section{(III) To boost status of human resource department}

In order to really realize role changes and boost the status of human resource department in an enterprise, human resource management department should be able to carefully ponder over and study problems under enterprise operation objectives so as to know actual operation situations and the cause influencing enterprise performance. Senior management layer should be able to promote company performance from the perspective of human resource management rather than only implementing the orders passively. Meanwhile, human resource department of an enterprise should know to implement key management. Daily affairs, such as employee recruitment, personnel training and salary administration can be carried out by professional enterprises. Beside, human resource department should spend much energy on research, prediction and communication as well as implementation of plans. At the same time, human resource department should transform to strategy planning and execution from previous administrative support to provide good value-added services for business departments. This requires human resource department understanding enterprise operation and management objectives more actively, the needs of each business department, enterprise functions, production, sales, values and enterprise cultural construction. In addition, human resource department should focus the objectives for design and penetrate the requirements for employees' skills, knowledge and attitude into many links so as to mobilize and develop the potential of employees. Furthermore, human resource management strategy and enterprise operation and management strategy should be mutually combined to support the company to achieve operation and management objectives. To really realize role changes, human resource management personnel should own the ability of enterprise operation and management.

\section{(IV) To form more perfect employee training system}

Construction of employee training system is extremely important for enterprise development. The establishment of sound and perfect employee training system contributes to developing and establishing personnel fruitful guarantee and perfection systems and decides the formation of fruitful competition and development mode. Enterprises should set up full-process employee training system to establish effective training system for employees' work and career. More flexible training and education systems should be established according to employees' features and enterprise development needs so as to provide comprehensive personnel guarantee for comprehensive enterprise development in each stage. Besides, the system can help fully exert the potential of employees and help them realize self-worth. This is also an important measure to establish learning-based organizations and form good enterprise culture. It is required to set up diversified training system, effectively form more flexible training system, realize combination of internal training and external training and enhance internal training system so as to cultivate important technical personnel and management personnel for enterprise development and then form effective personnel training and management.

\section{(V) To form fruitful incentive system}

Fruitful incentive system can more effectively motivate employees' work enthusiasm and promote employees to form great desire for objectives and self-actualization. Incentive mainly includes spiritual incentive material incentive, short term incentive and long-term incentive. Spiritual incentive focuses on praise. Company managers should popularize praise and other information carriers to the largest extent so as to motivate employees' sense of pride. Meanwhile, material incentive such as goods and money award should also be valued. Short term incentive refers to the award for some work. Money award and other forms can be adopted. Long-term incentive depends on employee promotion system and stock ownership incentive. The incentive system should be able to be successfully prepared and implemented to retain personnel and create miracles.

\section{(VI) To promote enterprise cultural construction}

Enterprise culture is an intangible resource and receives more and more attention from enterprise 
management layer. The establishment of enterprise culture is based on human resource management and goes through long-term unconscious influences. Enterprise management layer should penetrate their operation and management ideas, values and behavioral patterns into vast employees. Excellent enterprise culture will be certainly reflected in specific behaviors of the enterprise and even employees. Daly behaviors can reflect one's cultural level. Cultural level here not just refers to educational level, but also refers to cultural accomplishment. Thus, to cultivate high-quality personnel must start from their daily actions, habits and cultural learning in order to cultivate high-quality personnel with honesty, civilization and innovation awareness. To implement enterprise cultural construction in actions of every employee, the most effective means is to carry out human resource management and planning. Currently, although enterprise cultural construction gains certain development, the combination with enterprise human resource management is still insufficient. This is because the joint points between human resource management and enterprise cultural construction are not found out so that they only perform their own duties and cannot reach mutual difference and great unification. As a result, it is hard to form resultant force and reflect comprehensive management effects. So, the decision-making layer must give play to excellent coordination and communication functions, pay high attention to enterprise cultural construction, combine enterprise cultural construction with enterprise human resource management and drive effective execution of enterprise cultural construction through effective human resource management. In turn, favorable enterprise cultural construction can promote better implementation of enterprise human resource management.

\section{Conclusions}

In conclusion, human resource management is an important content for enterprises to carry out effective management. Enterprise human resource management should establish people-oriented development view so as to realize new management system combining individual career development and enterprise development. To improve core competitiveness, enterprises must work out feasible human resource management strategies according to plights of human resource management so as to effectively boost the level of human resource management.

\section{References}

[1] Dai Yuye, Exploration and analysis of incentive mechanism of human resource management [J]. Decision-Making \& Consultancy Newsletter, 2010 (2)

[2] Deng Zhenhui, Problems and solutions of enterprise human resource management [J]. China New Technologies and Products, 2010 (9)

[3] Zhang Fengwen, On problems of modern enterprise human resource management [J]. Market Modernization, 2011 (3)

[4] mai Bo, On reality problems of enhancing enterprise human resource management [J]. Foreign Investment in China, 2012 (19)

15] Li Mingxia, Problems and countermeasures of enterprise human resource management [J]. Market Modernization, 2012 (29)

[6] Huang Xiang, Problems and countermeasures of enterprise human resource management development in China [J]. Business Research, 2013, (16) 